\title{
Exploring the Exemplary STEAM Education in the U.S. as a Practical Educational Framework for Korea
}

\author{
Georgette Yakman · Hyonyong Lee* \\ Virginia Technology and Engineering Educators Association Past President \& STEAM Consultant • \\ ${ }^{1}$ Kyungpook National University
}

\begin{abstract}
Science, Technology, Engineering, and Mathematics (STEM) education in the U.S. has been identified as a significant national reform in K-16 education and curriculum in order to prepare students for the global economy of the 21 st century. Korea has been facing very similar challenges to improve science, technology and mathematics education, in particular, the affective aspect of learning science and mathematics. Science, Technology, Engineering, Arts, and Mathematics (STEAM) education has become a crucial issue in Korean education system. The major purpose of this exploratory study is to inform the exemplary framework of STEAM education in the U.S. for Korea and to provide descriptive and analytical accounts on STEAM teaching and learning as an innovative integrated convergence education. This study integrates the outcomes of research papers on STEM education and recent literature. It employs content analysis methodology qualitatively by analyzing and synthesizing the findings, conclusions, discussions, and recommendations of accumulated research works related to STEM/STEAM education. This study will help gain a stronger sense of the STEAM framework and will guide to develop the educational programs for Korea.
\end{abstract}

Key words: STEM education, STEAM education, framework, Science education, Technology education, Engineering education, Arts education, Mathematics education

\section{INTRODUCTION}

Science, Technology, Engineering, and Mathematics (STEM) education in the U.S. has been identified as a significant national reform in $\mathrm{K}-16$ education and curriculum in order to prepare students for the global economy of the 21st century. Professional communities of science, technology, engineering, and mathematics education have supported the movement of the integration among STEM education fields (AAAS, 1993, 1998; ITEA, 2000; NTCM, 1995, 2000; NAE, 2004, 2005; NRC, 1996 , 2012).

Korea has been facing very similar challenges to improve science, technology, mathematics education, in particular, the affective aspect of learning science and mathematics. PISA results indicated that the level of students' interests, motivations, and self-efficacy related to science learning was very low among OECD countries (OECD, 2007, 2010). Lee and Park (2010) also reported that elementary school students had a lack of accurate images of scientists and engineers. Engineers were depicted by wearing the laborer's clothing, working outdoors, building, fixing, and manufacturing. They suggested that the earlier exposure to technology and engineering in the elementary school classroom could help elementary school students form accurate and positive images of science and engineering.

Science, Technology, Engineering, Arts, and Mathematics (STEAM) education has just been implemented to enhance the understanding of the structure between the fields of science, technology, engineering, arts, and mathematics. STEAM education has become a crucial issue in Korean education system (Kwon et al., 2009; MEST, 2010; Sanders et al., 2011). The Korean

\footnotetext{
${ }^{*}$ Corresponding author: Hyonyong Lee(hlee@knu.ac.kr)

**Received on 31 July 2012, Accepted on 23 August 2012

***This research was supported by Basic Science Research Program through the National Research Foundation of Korea(NRF) funded by the Ministry of Education, Science and Technology (No. 2010-0026873).
} 
national organizations and professional communities of science and technology (e.g., KOFAC) agreed that the integrative approach in STEAM disciplines is a critical element to restructure school education (KOFAC, 2011; MEST, 2010). For example, the 2009 revised National Science Curriculum began to express the importance of the ideas of integration and convergence for STEAM education (MEST, 2011). KOFAC (2011) expressed that the implementation of STEAM education in Korea may enhance science, technology, engineering, arts and mathematics education. STEAM education can contribute to improve the global literacy of all students in their future of a new global era (MEST, 2010, 2011).

MEST(2012) and Baek et al.(2011, 2012) reported the major STEAM components and the framework of STEAM education. STEAM education has been designed with the framework that is very adaptable to all levels, types and styles of teaching. The framework is composed of 'Creative Design' and 'Emotional Learning' as a crucial element. In addition, the framework focuses the affective aspect of science, technology, mathematics education on 4CSTEAM stands for Caring, Creativity, Communication, and Convergence (Baek et al., 2011, 2012). The framework is intended to develop deeper understanding of content, process, and characteristics of science through 'Creative Design' and 'Emotional Learning'. Despite these efforts to implement and disseminate STEAM education to the schools, there have been no empirical studies of the implementation of the STEAM framework in real classroom contexts. This study is designed to inform the exemplary framework of STEAM education in the U.S. for Korea and to provide descriptive and analytical accounts on STEAM teaching and learning as an innovative integrated convergence education. This study integrates the outcomes of research papers on STEM education and recent literature. This study employs content analysis methodology qualitatively by analyzing and synthesizing the findings, conclusions, discussions, and recommendations of accumulated research works related to STEM/STEAM education (Merriam, 1998, 2009). This study will help gain a stronger sense of the STEAM framework and will guide to develop the educational programs for Korea.

\section{FINDINGS}

\section{1) STEM to STEAM for functional literacy}

STEAM is a relatively new framework of educating across the disciplines. It has been evolving to support a new educational theory. STEAM is based on STEM education, which grew out of the vast need to have more students achieve success in understanding the systems and connections (Baek et al., 2011; Yakman, 2008) that bind together the hard sciences, technology, engineering and mathematics, in order to help solve the problems of a rapidly changing world (Dakers, 2006). This concept has received recent emphasis, that it has created a new educational branch, STEM, which can be defined in two ways:

1) The more traditional way, we like to write as $\mathrm{S}-\mathrm{T}-\mathrm{E}-\mathrm{M}$ education, as it is the individual 'silo' fields of science, technology, engineering and mathematics education. Each has evolved to formally include elements of the others within their own standards and practices (AACTE, 2007).

2) The newer trend is the concept of integrated STEM education. It includes the teaching and learning practices when the subjects are purposefully integrated. When taught, one field may be the dominant base field, or all may be blended unilaterally (Sanders, 2006).

While studying the common factors of teaching and learning across the disciplines of $\mathrm{S}-\mathrm{T}-\mathrm{E}-\mathrm{M}$, it was hard to not include the influences of the arts disciplines. The arts contain all of the divisions that interact with the pure possibilities of combining the other fields to 
shape the direction of development. Based on that fact it is necessary to include the key elements of the arts such as; aesthetics, ergonomics, sociology, psychology, philosophy and education into the study of the $\mathrm{S}-\mathrm{T}-\mathrm{E}-\mathrm{M}$ concepts that we supposed to go on and shape our developing world and cultures? This concept began the development of an educational framework that could formally link the study of the hard sciences to that of the divisions of the arts. This investigation led to a deeper study of each of the main subject areas with the hope that the finer educational divisions could be classified as having value and influence within each of the other silo disciplines including all the areas of social, fine and physical arts. The following gives the base definitions that are the result of our investigation:

- Science - what exists naturally \& how it is affected (Rutherford \& Ahlgren, 1989)

- Technology - what is human-made or "innovation, change, or modification of the natural environment to satisfy perceived human needs and wants" (ITEA, 2000)

- "is any modification of the natural world made to fulfill human needs or desires"

(NRC, 2012, p. 202).

- Engineering - "is a systematic and often iterative approach to designing objects, processes, and systems to meet human needs and wants" (NRC, 2012, p. 202).

- Mathematics - the study of numbers, symbolic relationships, patterns, shapes, uncertainty \& reasoning. (AAAS, 1993 \& NCTM, 2000)

- Arts - Fine, Language \& Liberal, Motor and Physical

- Language Arts: The way that all kinds of communication is used \& interpreted (Patterson). Includes Music

- Physical Arts: manual and athletics arts including ergonomic movements (NASPE, 2004).

- Liberal Arts(Social): Including; Education,
History, Philosophy, Politics, Psychology, Sociology, Theology, Science Technology Society (STS) and more $\cdots$ (Featherstone, 1986)

- Fine Arts: Aesthetics, where the oldest sustainable cultural pieces come from that teach of the earliest records in civilizations (Mishook \& Kornhaber, 2006).

Unraveling the fields of the social, fine, manual, physical and liberal arts led to an understanding of how they expand outwards to influence and be influenced by the studies and practices of the $\mathrm{S}-\mathrm{T}-\mathrm{E}-\mathrm{M}$ fields. All of this investigation led to the development of the STEAM framework to help educators teach subjects more like they are related to one another in reality. From all of these connections, following diagram was created as a way to establish a framework to give structure to and analyze the interactive nature of both the practice and study of the formal fields of science, technology, engineering, mathematics and the arts (figure 1).

STEAM-style education can be enjoyably and meaningfully delivered in more engaging and deeply embedding ways within the already wellestablished realm of education. The philosophy of STEAM revolves around the concept that: STEAM = Science \& Technology interpreted through Engineering \& the Arts, all based in Mathematical elements (Yakman, 2008). A significant common thread is that each primary division promotes a need for students to develop a proficiency in the subject that would make them literate enough in the discipline to be able to continue to adapt to and learn about the basic developments that the field takes. When looking across the breadth of the categories, We can point to a significant amount of research done on how to instill scientific literacy, technological literacy, the design process, mathematical literacy and language literacy in students (Driver et al., 1994). We would argue that this leads to a conclusion that students need a literacy of a 


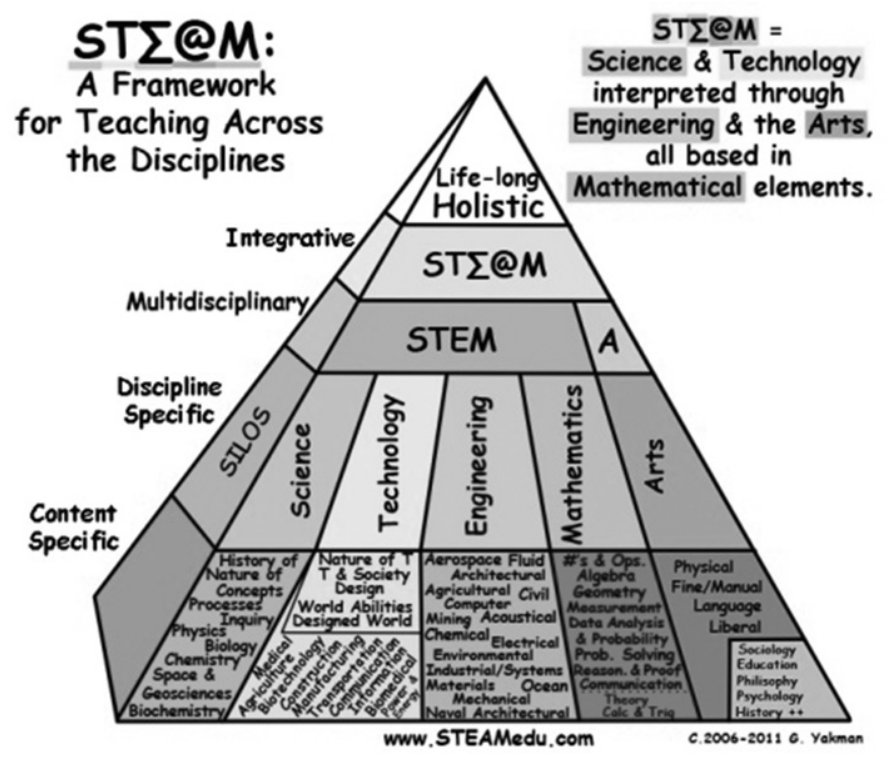

Fig. 1 STEAM: A framework for teaching across the disciplines (Yakman, 2008)

breadth of the primary disciplines which would include an ability to transfer knowledge with higher order thinking between disciplines so that students may obtain a functional literacy (DeBoer, 1991; Yakman, 2008). Disciplinespecific thinking is transferable to other bases of content. Functionally literate people are more effective because they know how to think across the spectrum of topics and understand the connections between the disciplines. Students engaged with STEAM, not only learn to be literate in a singular (silo) field, but they become life-long learners who are much more capable of adapting to and advancing the global society. This also assists them to better understand people and things rooted in other disciplines, perspectives and cultures so they can communicate and work with one another while still maintain their own identities.

\section{2) Discipline-based STEAM}

It is important that each subject still maintain its own educational base in the disciplines, so that "scholars of teaching and learning can address field-specific issues if they are going to be heard in their own disciplines, and they must speak in a language that their colleagues understand." It is also important that each division be taught with formal acknowledgment of the commons between all the disciplines, because "the easier it is to engage other subjects, due to factors like common language, the easier it is for students to realize how to apply knowledge from one curriculum to another." (Huber \& Morrale, 2002, p. 2). Despite the fact that science (the natural world) precedes technology (human-made items), science and technology are independent disciplines with different goals, methods and outcomes, yet technology ontology (study and development) predates science ontology (study and investigation) in a dialectical relationship with neither a dominant partner (Gardner, 1997). With this knowledge, the use of the word 'study' is correct for both fields, in science it relates more to the definition of something being analyzed on how it naturally occurred, versus in technology it relates to defining the way in which something can be artificially constructed. The vocabulary is the same, but the relationship to the individual discipline is the key to understanding what the vocabulary refers to in differing contexts. When students are aware of 
these contexts, their depth of knowledge is broadened and deepened by the transference of knowledge from one discipline topic to another. Cooperation among disciplines provides realistic dynamics and influences that allow students to learn how to accommodate to the real world. Cooperation can also have the effect of encouraging the use of common language, common analogies and an appropriate level of detail across the two subjects thus avoiding misconceptions and regression" (Barlex \& Pitt, 2000, p. 41). If you add in an understanding of the nuances and variations in meanings between languages such as Korean and English, one's understanding of the known world in the global context becomes exponentially better. If more people understood that Korean, or 'hangeul' was originally called "Hunminjeongeum," which means "the right sounds to enlighten the people" and that it is the most recognized worldwide as the most scientific and logical writing system, marked by ingenuity and efficiency and an ease to learn (KBS, 2011a), it would add to a better global understanding of the culture of Korea and logically have an influence to promote more respect for Korean equity, especially in the business and engineering fields. But to be more thoroughly understood, one must master the arts of communication that go well beyond spoken and written languages.

\section{3) Mathematics as a universal base language}

The relatively recent Kuhnian revolution in the field of mathematics education has some fascinating implications for all fields (Ernest, 1994). "It's time to let the secret out: mathematics is not primarily a matter of plugging numbers into formulas and performing rote computations. It is a way of thinking and questioning that may be unfamiliar to many of us, but is available to almost all of us" (Paulos, 1995, p. 3). This led to an exploration of the intrinsic elements that show that mathematics is the base element of social constructivism for the other silos, although it is not infallible as such. Mathematics, and mathematics alone, is essential for the study of the other silos, it is even the base of the study of language (Hersh, 1994, p. 14). Mathematics is the primal language that cuts across all other field's boundaries, which is the closest the world has to a common language that can be currently used to provide structure for the other silos. In 1978, Schawab introduced the four 'commonplaces of teaching mathematics'. These are the subject (mathematics), the learner of mathematics, the mathematics teacher, and the milieu of teaching, including the relationship of mathematics teaching and learning, and its aims, to society in general (Ernest, 1994, p. 3). It is this last statement about mathematics' relationship to society, which brings in a wealth of applicable constructivist elements. The study of technology and engineering is not possible without the study of the natural sciences. This in turn cannot be understood in depth without a fundamental understanding of mathematics. Mathematics is not just a primal language but a network of practical and theoretical divisions of varying methods includes projects, constructions, analysis and process work, as well as (instead of solely) the results that interact with other subjects as well as stands alone as a branch of natural science (NCTM, 2000). It is a field necessary for all kinds of learners, overall concepts of theory, history \& applications. It is truly reality-based in that way that it is the primary analyzing tool for all practices, applications, values, testing and assessment of any element of society and nature, including education (Dewey, 1916; NCTM, 1995). It not only relates to all aspects of society, but as a finite language, mathematics can also transform culture (Paulos, 1995), so it needs to be expressed carefully and accurately.

\section{4) Relationships between education \& reality for convergence}

The commons of language arts used to teach 
across the disciplines directly supports transference of knowledge between subjects, becoming another extension of that same concept to believe that a commons of epistemology, pedagogy and methodology would also be beneficial to deeper and broader understandings, despite the context of a specific discipline. This is not to say that a singular unified language or method is best, but more accurately to say that a variety of well-explored and planned uses of languages and methodologies would help to establish more connections to knowledge, resulting in a more substantial level of understanding across the disciplines. There needs to be an exploration of existing views to create new theoretical ideas, experimental work and cross-discipline, consensus-approved language styles (Barlex \& Pitt, 2000). John Dewey, educational researcher and practitioner, has a great deal to say on the topic. One of his most succinct quotes is this: 'experience that is integrated - that which attains the fullest possible meaning - is a primary goal of human activity $\cdots$ growth under the circumstances of life as an ongoing experiment involves risk and the willingness to relinquish the authority of tradition, but it should enable the person, as well an entire society, to look critically at previously accepted beliefs in the light of new experience' (Dewey, 1916). It is within that quote that Dewey both reveals the reasons for the need of integrated, reality-based, inquiry learning as well as the primary reasons why it has yet to be adopted. Although it is essential to teach people to work within a society to advance the global culture, it is very difficult to create real-world experiences in a classroom atmosphere and equally as demanding to do so within any particular culture and the established beliefs affiliated with it, this latter concept can be termed the 'Galileo effect.' By using the term 'Galileo effect,' it is in reference to the societal resistance when European culture transferred from the practice of alchemy into the study of science. The resistance to Galileo's ideas is a prime example of societal established norms being so powerful, that even when scientific and technological evidence proves such beliefs to be false, there is a great pressure to dismiss logical advancements and continue to function in long-accepted traditions. Every culture is guilty of this, because it is by established cultural 'rules' that societies have advanced enough to get where we are today. All cultures that have survived, have seen others destroyed by holding fast to their out-dated beliefs as well as have seen some cultures destroyed by adopting too quickly new positions that were believed and adhered to before proven. Therefore, it is at the heart of the essence of educating, to provide students the means by which to advance knowledge and also the common sense by which to test and prove the theories affiliated with intellectual advancements.

\section{5) Integrative basis for education}

STEAM tries to help solve the above-described educational dilemma, by not specifically teaching any one group of topics, but instead by teaching students content in ways that also teach them how to interpret the vast changes they will encounter in their lifetimes. STEAM does this by teaching students to adopt the attitudes, habits and intellectual skills to be adaptable life-long learners. "The idea that it is impossible to teach people to think, $\cdots$ did not proceed from scholarly research, but from an unscholarly assumption that if thinking was not being taught, and had not been taught, it therefore could not be taught." (Ruggiero, 1988). STEAM is a substantiated, economical and sociologically adaptable as a framework by which to transition, maintain, create and evolve educational elements, programs and institutions to include multidisciplinary-oriented practices catering to developing more functional citizens. The goal of STEAM is to be strong, benchmarked, measurable and easily reinforcing 
of standards in unique and engaging ways. It is also planned in order for it to be accepted into many different types and levels of learning environments. It has been created to be adaptable so that it can accurately be representative of the surrounding culture and built to be tolerant of all types of diversity both, within those represented who are studying with it and for all of the cultures known to them. STEAM is a plan for public, common education where all subjects and types of types of learners can validly contribute and all effort is encouraged and measurable for group and individual achievements. STEAM can be implemented to be engaging, hands-on and reality-based, yet inexpensively, with many extensions to draw education, industry, government and the community together for the common good of bettering public education for all, while meeting standard's guidelines and STEM related goals.

When students deeply believe that one person can make a major difference in a global economy, they feel empowered to succeed personally, culturally and for the betterment of all. They become invested in a competitiveness that still fosters community spirit. It doesn't contradict, but actually assists the efforts of "harsh competition-oriented and successoriented parenting goals (Hwang, 2011), while encouraging students to genuinely feel that encouraging their peers and learning from one another is to everyone's benefit. The key to unleashing that power in whole classes of students is to, from the beginning, embed meaningful challenges and individual assessments into teams with a wide array of strengths so that everyone has a place to be recognized for their advanced skills while also having personal interactions and respect for those with other strengths that balance theirs.

\section{6) Different styles of integrated learning}

Holistic education in the STEAM context is denoted as life-long learning; therefore all purposefully planned programs of teaching that have been called holistic education, are considered an attempt at it. It can be argued that holistic learning cannot be controlled or planned; it is the interpretation of each person's sphere, or universe, of influence. The results of these influences, both internal and external, greatly shape what people do with what they are exposed to and what they understand. Since each person's perspective is different, holistic education cannot be delivered equally to students. As can be seen in Figure 1, this is why the very top of the STEAM pyramid is the universal level, as it is where individuals learn from their environments that are not possible to be controlled for true planned 'holistic learning.' The next level is denoted as 'STEAM' in the pyramid to establish a place for planned integration. It is at this level where students can obtain a broad scope of all the fields and a basic overview of how they inter-relate in reality by teaching them with a purposefully planned and reality-based interdependence. It is at this stage that students begin to understand what and how to explore all areas of opportunities in the educational realm. Instructors have the choice of focusing in depth on specific areas or covering a broad scope of the topic. Teams of teachers can work together to provide in depth coverage of their areas of expertise while reinforcing what students are learning in other specific areas. The next level denoted on the diagram is the multidisciplinary level. It is at this level where students can obtain a scope of specifically chosen fields and a concentrated overview of how they inter-relate in reality. An excellent way to teach about natural inter-relations in practice of both STEM and STEAM is to teach realitybased/authentic units. When purposefully planned to cover certain fields and concepts, instructors can still easily use themed education, but with integration the fields should be represented in a more balanced way. Whereas with multidisciplinary levels, the fields not in 
primary focus should not be all together excluded from the curriculum, but instead, at least explained as being an element of the scope that would occur in reality. The next level of the diagram is the discipline specific level. It is at this level where individual silo divisions of fields, or disciplines, are taught at focus levels and where individual subjects are the primary topic of focus. This is not to say that other subjects are excluded, subjects should still be covered contextually. The primary subject is explored significantly more in depth then the related fields. This is the level at which to explore what areas of expertise a person wishes to acquire as career and hobby. The most specific level of the pyramid is the content specific level. It is at this level that content areas are studied in detail. It is here where professional development happens and students delve into the tighter realm of the specific content areas of their interest. Areas can be studied alone or in specifically grouped clusters from within their own silos or from across the fields. Again, this should still be relevant and contextual to the world at large, but this is the point where educational and professional practice most fully interrelates with each other's developments.

Current trends in education have already established STEM as a relevant block of core fields. Trends have also shown many of the branches of the arts being more and more marginalized. In most public education, only the language arts and social studies are still formally given substantive attention as having importance outside of the STEM areas. This can be seen a tragedy, as it eliminates many primary ways for students to obtain contextual understanding of all fields. Therefore, as students are exposed to prominent and marginalized fields, they begin to understand the hierarchy and politics of both education and practice. It is here that students might begin to have a concept of specific areas of interest to explore as potential career paths and subsequently be turned away from investigating fields that are not dominantly represented by people in they feel connected to. With the 'flattening of the world' through the advancements of technology, we are approaching a time where people from anywhere in the world, from any socio-economic backgrounds have more and more access to any type of career they wish to pursue and every country is doing its best to educationally evolve as rapidly as possible to keep up with such changes. STEAM has been purposely developed to be adaptable to changes so that it does not become a dated method.

\section{7) Epistemology leading to STEAM}

STEAM is 'built on the educational giants' before it and tries to promote the overlapping trends that are geared at educating the whole learner. The most closely aligned trends already being used and tested pedagogies and curricula fall under the titles of integrated, themed, inquiry, discovery or reality-based and constructivist education (Barlex \& Pitt, 2000; Dewey, 1916; Petrina, 1998). The six primary features of constructivism are: Engagement, understanding, performance, reflection, generativity \& commitment (Furth, 1970). STEAM aligns well with many educational theories and instructional strategies already widely accepted such as: Constructivism, which includes a tenants that directly relates it to liberal education and openly adheres to no sole or best method or simple rules for pedagogy, but instead is universally adaptable and open to interpretation and implementations and it ideal for integrative learning (Dakers, 2006; de Vries, 1996; Lauda, 1980; ITEA, 2000; Salinger, 2005; Wicklein \& John, 1995; Zuga, 1993) with there being no fixed borders between the disciplines, but instead, insists on illustrating the necessary cross-links for relatively and reality (Rutherford \& Ahlgren, 1989) with its only restriction being that it is used to teach how to learn, not what to learn (Furth, 1970). Many specific terms are used 
as aspects of these trends that promote educating the whole learner in an interdisciplinary realitybased team manner. "Learners as discoverers," "team sharing participants," multiple perspectives and roles, teacher as guide, observer and cooperator or co-learner, situational and potentially contradicting to beliefs being explored for whys and why-nots, realistic and relevant environments and lessons, contextual subjects, methods and skill development, application and problem-solving decision based learning (Dewey, 1916; Furth, 1970) scaffolding and proximal development by Vygotsky (Driscoll, 2005) 'Multiple Intelligences' by Gardner (Berger \& Pollman, 1996), 'Marzano' s Strategies (Marzano, 2007), interrelated discipline recognitions with interdependent advances and integrated SMT and STEM (LaPorte \& Sanders, 1993), learning how to learn and/or guided discovery (DeBoer, 1991; Driver et al., 1994; Froebel, 1947; Ruggiero, 1998), teacher and student collaborative learning, (Barlex \& Pitt, 2000; Freire, 1996) 'Actor Network Theory,' (Latour \& Woolgar, 1986) critical and higher order thinking '(Bloom, 1974)'s Taxonomy', socio-cultural ethical perspectives (Driscoll, 2005), commons of disciplines used by all, (Huber \& Hutchings, 2005) deductive reasoning and discourse, small group interactions, modeling, whole learner applications (indigenous tribes, Reggio Emilia, Montessori, Waldorf and home schooling movements (Firlik, 1996; Minnis \& John-Steiner, 2005; Montessori, 1975). Bruner explains the concept of 'sociocognitive conflict' where experiences trigger people to remember related events which they did not or do not currently understand in order to create an assimilation through connections that will decrease their confusion in an effort to make sense of their interactions and environment (Rogers, 1969). This concept is also in line with the concept of Science and Technology in Society (STS) and how societies revolve in influence with technology being reliant on each other and victims of each other as development happens. (Pinch \& Bijker, 1994). There are many more epistemologists educational psychologists whose work also supports and are encompassed by the STEAM framework. Although they have not been formally included in mass, there are also numerous cognitive scientist's work that also support this framework for people of all age. With the ongoing research, development, implementation and refinement of STEAM, I continue to find more substantive backing for its use and have been avidly seeking faults in it to address.

When one looks at the subjects traditionally taught in modern education, most cultures put the most emphasis on science, language arts, mathematics and the social sciences as they relate to their specific culture. Although they are not regularly included in subjects taught at most K-12 schools, the fields' technology and education are the ones that, in reality, most easily transcend the boundaries of all the disciplines, in order for their progression to have been established and continue to flourish. "Technology education became one of the few areas of study to adopt a structure (from its beginning) that allows for, and encourages, changes in its core structure to accommodate changes in the technological world that interrelate with society in a very reciprocal way (Zuga, 1993). Engineering has been mostly being taught under the divisions of technology education as it does not have a history of ever being taught as a silo discipline in $\mathrm{K}-12$ until very recently. This has resulted from the fact that by its nature, engineering is interconnected to the advances in all of the other fields and has primarily been developed above the $\mathrm{K}-12$ realm due to its complexities and has not bonded to a core curriculum to provide a base from which to be formally taught. Since it is based in a language of mathematics, it has been the field with which to transcend language boundaries most easily to support global extraction, production distribution and consumption of its products. The company IKEA is a prime example of this concept as the directions for the products are all sketches and numbered sequences so that they do not have to 
be translated to other languages. This concept also helps prove that developments in the fields of engineering and technology does not require much in the way of language arts, it requires ingenuity, but in order to share any concepts that have been developed, there needs to be a common language that goes beyond the literal translations of mathematics to engage the humanity behind the acceptance of new things. Technology education is the niche in the $\mathrm{K}-12$ arena where the resulting products of engineering's processes are learned about and studied. Without this field opening the door for younger people to explore the physical concepts behind design, individuals who are more creative gravitate towards the fine and musical arts. As illustrated well by Leonardo DaVinci's life, the fine and musical arts can develop by means of a precise concentration of creativity and mathematics, but it is with the addition of more substantial mathematics, science, and sometimes ergonomics that defines the difference between the emotions conjured by art and the usefulness of technological devices. Specifically, the field of engineering being a team-based enterprise, representing the research and design of creating new solutions to problems, is a subset of the field of technology. Thus, the technology laboratory, previously conceptualized as a place to make things, has graduated into more of a place to learn the interconnections of things (Zuga, 1993). This fact has made it possible for engineering to start making an appearance in $\mathrm{K}-12$ education, especially at the middle and high school levels where students are capable of developing more advanced solutions to problems. The structure of most elementary school having a single teacher to deliver most of the curriculum allows for ease of thematic integration and introductory technology and engineering lessons to be implemented. Both technologists and engineers need to have the following abilities, the technologists to use and maintain the products that engineers continue to develop and reinvent. Those abilities include: Evaluating needs, wants \& opportunities, applying mathematics, science and technology, designing \& conducting experiments, analyzing and interpreting data, designing systems, components or processes, working in multi-disciplinary teams, formulating and solving problems effectively and responsibly, communicating effectively, engaging in life-long learning of contemporary issues, techniques and skills.

In order to develop students who have enough of an understanding of the $\mathrm{S}-\mathrm{T}-\mathrm{E}-\mathrm{M}$ topics to make educated decisions about which careers they care to devote their lives to, students must be given ample opportunity to engage with those topics. Korea is very advanced in the structure by which it offers compulsory education in a very broad spectrum of subjects through the majority of its $\mathrm{K}-12$ grades. A substantial difference between Korean middle school structure, and that which is used in America, is that the students stay in the classroom, while the teachers rotate to teach them different topics. This is much more conducive for learning in that students do not have to put away all everything from one topic to formally transition to another. This set up also makes it much easier for teachers to work with a common theme that can be established in a classroom and used as a thread to tie discipline concepts together. In American middle schools, all of the prompts and aids used to illustrate points in each subject are not available for other teachers to use in order to provide more connections to learning for the students. This also makes it more difficult for assessment to change in America, there is a lot of time wasted getting students ready to leave a class and getting settled into the new one and there is no central location for ongoing projects to be kept where multiple students and teachers can build on them throughout the semester. Korean "teachers are encouraged to" branch out from traditional teacher-oriented instruction methods to use a combination of pedogogical methods (including the inquiry mode, dilemma discussion, and student-centered instruction) so as to make a class meaningful, effective, and enjoyable and to 
stimulate and develop the thinking abilities of students" (Chu \& Park, 1996). The Korean elementary and middle school structure is very accommodating for the trend to keep developing. Having the Standards Olympiad provides students with a practical competition where students find out how to solve inconvenient cases stemming from lack of standardization (Choi, 2011), this sounds like an opportunity to further develop with STEAM framework integrations. Beyond that, it is commendable that community service projects were implemented as required extracurricular activities in both middle and high schools almost a decade ago (Onishi, 2006). Korea has an excellent existing framework by which to be an exemplary place to work towards a system of subject integration.

\section{8) Assessment}

The area of STEAM most recently being refined is assessment. The primary assessment tactic used with STEAM is a backwards design (Wiggins \& McTighe, 2005) team-based portfolio project of creating generic titles for each type of strength distributed for the skills needed for each type of team project. One way it was thought to be used within this structure, was having one or two students be assigned to be the lead or co-captains of one or multiple job titles. The grading can be broken down to the same general portfolio building and rubric structure. All the elements of the project and how they are evaluated are explained in advance with the instructions for fulfilling the requirements for the portfolio due at the end of the project. Students can see the checkpoints and get feedback, credit and encouragement for their work throughout the process. Various assessment techniques can be embedded in the portfolios, such as personal observations, interviews, check-lists, attitude scales, questionnaires written tests and more. Each title area of the project is given an equivalent point value, for instance, to use STEAM, each of the divisions receives 20/100 points, with partial points being also awarded. Grading is done continually through the process, but when it the project is completed and the grades are finalized, all students on the team receive a grade consisting of the total of team points acquired for each division averaged with the grades from the topic(s) they were the leader on. To illustrate this, let's say that at the end of the project grades are assigned as the ' $\mathrm{S}$ ' component getting 18 points, the ' $\mathrm{T}$ ' getting 17 , the 'E' getting 15, the 'A' getting 16 and the ' $M$ ' getting 12. All of the students will have 78 for their group grade, which will get averaged with the equivalent of the grade that each student was in charge of directing, recording and reporting for the project, if a student was assigned to lead or $\mathrm{co}^{-}$ captain two or more areas, those grades are averaged before the individual grade is averaged with the team average for a final grade. So, a student leading 'S' would get 18/20 =90\% averaged with $78 \%$ equals $84 \%$ for a final grade, where as a student leading ' $\mathrm{T}$ ' and ' $\mathrm{E}$ ' would get $32 / 40=$ $80 \%$ averaged with $78 \%$ equals $79 \%$ for a final grade. Hopefully, all of our students do better than these examples. This way each student is held accountable for the whole team's efforts and results as well as their own specific grade for how they did with the area of the project that they possessed specific skills for and the averaged final project grade reflects both equally. Students adapt very quickly to helping each other succeed and doing all they can as individuals to take charge of encouraging, helping and guiding their team as leaders and participants. Since no one student is in charge, no one maintains the power in the group. Students who get particularly interested in a specific part of the project are encouraged to build up that area of the team's portfolio and explore related topics. It is also very helpful since students tend to befriend others with similar skills socially, it affords students an opportunity in an academic setting to not only 
see the value of others with different types of skills, but to obtain in-depth knowledge as to how other types of people think, react and process information. This leads to a type of working and societal community knowledge that cannot be taught without experience. Students who are excellent at rote memorization and regularly receive excellent grades on memory based tests are often given more affirmation of their accomplishments than those who do not excel at memorization. With this structure, those students who are excellent at understanding processes and creating new things can be recognized as skilled designers, technicians and engineers. Even students with significant limitations are offered ways to not only participate, but to teach others on the team. Often teams who have students who would not be great friends outside of the classroom come to appreciate the skills and perspectives of the rest of their teammates who are usually different from them. It has been very exciting to see students who have not understood each other's perspectives previously suddenly encourage and thank each other for contributing their skills to the project. STEAM teams evolve into communities and connections are made that extend far beyond the classroom.

\section{CONCLUSIONS}

Both the reasoning of why there is a global movement towards developing more people in the $\mathrm{S}-\mathrm{T}-\mathrm{E}-\mathrm{M}$ fields, and the knowledge that there is something about these 'hard' fields that make many choose paths of liberal arts studies, especially women and minorities, makes the concept of STEAM not only more than a possibility. It is critical for global culture that students be interested in these fields as well as be able to succeed in learning and developing themselves with professional and realistic attitudes and skills. As Dewey (1916) said, the disharmony between textbooks and students' life-experiences creates problems with motivation and transfer of learning. With STEAM, students create their own portfolio texts so that their knowledge is as current as possible and they solve real-life problems that empower them as well as deeply seed their knowledge in multiple ways for transference.

Many of the arguments laid out here for the adoption of this framework can be promoted in additional ways for more reasons including; this way of teaching helping prove that your students can learn more and deeper for less money and be ecologically responsible. This and the results of students being easier for businesses to train will help with a deeper interest in business donations and involvement in education. If students are encouraged to explore projects that fill community needs the community itself will immediately benefit and be behind promoting the growth of similar programs. Breaking down the walls of the disciplines 'silos' will help teachers to work more closely with each other to support each other's goals while still giving each other the space to teach in the ways that work best for their topic, their particular students and themselves. The bottom line is that no matter what country students are in, public education needs to progress with a rapidly changing technological society while supporting more students with less resources and money and STEAM is a way to continue that effort with a flexible, globally responsible and respectful structure.

It is impressive that the Korean flag with its white background, taegeuk pattern, and four trigrams signify peace, unity, benevolence, justice, wisdom, courtesy (kibun) a ying (id) and yang (ego) balance, creation, hope, integrity and eternity all in a constant revolving pursuit of perfection. (KBS, 2011b). All of these things are promoted in the STEAM framework as it is the hope that more countries than Korea will base their community efforts on these humanistic values, so that no matter how distinct people and countries can be from each other, there is acceptance of differences while understanding 
that there is a unifying force of humanity that all people embody and are responsible for cultivating as we all interact with the universe. Because this responsibility relies on the efforts of all people, STEAM education has been developed with the hopes that it is useful to learn about for all people, but that it is originally focused for those in formal education including; administrators, legislators, educators, students and that from there it will spread to the general community. STEAM can help make good education better. The STEAM framework, like steam itself, can fit anywhere and take innumerable shapes, and if used purposely can be a very powerful and enjoyable tool for teaching and learning any level of any topic.

\section{References}

American Association for the Advancement of Science [AAAS]. (1993). Benchmarks for science literacy. New York: Oxford University Press.

American Association for the Advancement of Science [AAAS]. (1998). Blueprints for reform. New York: Oxford University Press.

American Association of Colleges for Teacher Education [AACTE]. (2007). Preparing STEM Teachers: The Key to Global Competitiveness. Washington, DC: Author.

Baek, Y., Park, H., Kim, Y., Noh, S., Park, JY, Lee, J., Jeong, J-S, Choi, Y., \& Han, H. (2011). Steam education in Korea. Journal of Learner-Centered Curriculum and Instruction, 11(4), 149-171. (in Korean).

Baek, Y., Kim, Y., Noh, S., Park, H., Lee, J., Jeong, J-S, Choi, Y., Han, H., \& Choi, J. (2012). Basic research for establishing the direction of STEAM education in Korea. Korea Foundation for the Advancement of Science and Creativity.

Barlex, D., \& Pitt, J. (2000). Interaction: the relationship between science and design and technology in the secondary school curriculum. London: Engineering Council. p. 41

Berger, E. H., \& Pollman, M. J. (1996). Multiple Intelligences: Enabling Diverse
Learning. Early Childhood Education Journal, 23(4), 249.

Bloom, B. S. (1974). An introduction to mastery learning theory. In J. H. Block (Ed.), Schools, society and mastery learning. New York: Holt, Rinehart and Winston.

Choi, K. (2011). Lifelong learning Korea's strategy for standards education. http://www.iso. org/iso/bonus_korea_strategy_for_eduction Accessed: April 20, 2011.

Chu, B. \& Park, J. (1996). Moral education in Korea: Curriculum and teacher education. Paper presented at the annual conference of the Georgia Council for the Social Studies, Atlanta, GA.

Dakers, J. R. (2006). Towards a philosophy for technology education. Defining Technological Literacy: Towards an epistemological framework. New York: Palgrave Macmillan.

de Vries, M. J. (1996). Technology education: Beyond the technology is applied science. Journal of Technology Education, 8(1), 7-15.

DeBoer, G. E. (1991). A History of Ideas in Science Education: Implications for practice. New York: Teachers College, Columbia University.

Dewey, J. (1916). Democracy and education. New York: Macmillan Publishing Company.

Driscoll, M. P. (2005). Constructivism. In Psychology of learning for instruction. New York: Pearson.

Driver, D., Asoko, H., Leach, J., Mortimer, E., \& Scott, P. (1994). Constructing scientific knowledge in the classroom. Educational Researcher, 23(7), 8.

Ernest, P. (Ed.). (1994). Mathematics, Education and Philosophy: An international perspective. Washington, DC: Falmer Press.

Featherstone, J. L. (1986). Forward. In B. Kimball (Ed.), Orators \& philosophers: A history of the idea of liberal education. New York: Teacher College Press.

Firlik, R. (1996). Can We Adapt the Philosophies and Practices of Reggio Emilia, Italy, for Use in American Schools? Early Childhood Education Journal, 23(4), 217. 
Freire, P. (1996). Pedagogy of the oppressed. New York: Continuum International Publishing Group Inc.

Froebel. (1947). Froebel. In R. Ulich (Ed.), Three thousand years of educational wisdom: Selections from great documents. Cambridge, MA: Harvard University Press.

Furth, H. G. (1970). Piaget for teachers. Englewood Cliffs, NJ: Prentice-Hall Inc.

Gardner, P. L. (1997). The Roots of Technology and Science: A Philosophical and Historical View. International Journal of Technology and Design Education, 7(1-2).

Hersh, R. (1994). Fresh Breezes in the Philosophy of Mathematics. In P. Ernest (Ed.), Mathematics, education and philosophy: An international perspective Washington, D.C.: Falmer Press.

Huber, M. T., \& Hutchings, P. (2005). The advancement of learning: Building the teaching commons. San Francisco: Jossey-Bass.

Huber, M. T., \& Morreale, S. P. (2002). Disciplinary styles in the scholarship of teaching and learning: Exploring common ground. Washington, D.C.: American Association for Higher Education and The Carnegie Foundation for the Advancement of Teaching.

Hwang, C. (March 27, 2011). "한국 청소년 '공 동체 의식 희박" Yonhap News. http://www. yonhapnews.co.kr/bulletin/2011/03/26/02000000 00AKR20110326064600004.HTML. Retrieved April 17th, 2011. (in Korean).

International Technology Education Association [ITEA]. (2000). Standards for technological literacy: Content for the study of technology. Reston VA: Author.

KBS. (2011a). KBS World - Language. http://rki.kbs.co.kr/english/korea/aboutkorea/ korea_aboutlanguage.htm. Accessed: April 20, 2011

KBS. (2011b). KBS World Symbol. http://rki. kbs.co.kr/english/korea/aboutkorea/ korea_ aboutsymbol.htm. Accessed: April 20, 2011

Korea Foundation for the Advancement of Science and Creativity[KOFAC]. (2011). STEAM Education. Seoul: KOFAC.
Kwon, H., Park, K. \& Lee, H. (2009). Research Trends on the Integrative Efforts in Technology Education: Reviews of the Relevant Journals. Secondary Education Research, 57(1), 245-274.

Laporte, J., \& Sanders, M. (1993). The T/S/M integration project. The Technology Teacher, 52(6), 5 .

Latour, B., \& Woolgar, S. (1986). Laboratory life: the construction of scientific facts. Princeton, NJ: Princeton University Press.

Lauda, D. P. (1980). Technology Education: A Concept in Transition. Paper presented at the Technology Education Symposium 80.

Lee, H., \& Park. K. (2010). Elementary School Students' Images of Scientists and Engineers, Journal of Korean Practical Arts Education, 16(4), 61-82. (in Korean)

Marzano, R. (2007). The Art and Science of Teaching: A Comprehensive Framework for Effective Instruction. Alexandria, VA: Association for Supervision and Curriculum Development.

Merriam, S. B. (1998). Case study research in education. San Francisco, CA: Jossey-Bass Publishers.

Merriam, S. B. (2009). Qualitative research: A guide to design and implementation. San Francisco, CA: Jossey-Bass Publishers.

Ministry of Education, Science and Technology [MEST]. (2010). The $2^{\text {nd }}$ National Master Plan for Science and Technology Education. Seoul: MEST.

Ministry of Education, Science and Technology [MEST]. (2011). The 2009 revised science curriculum. Seoul: MEST.

Ministry of Education, Science and Technology [MEST]. (2012). 2012 national plan for STEAM education. Seoul: MEST.

Minnis, M., \& John-Steiner, V. (2005). The Challenge of Integration in Interdisciplinary Education. New Directions for Teaching and Learning, 2005(102), 45.

Mishook, J. J., \& Kornhaber, M. L. (2006). Arts Integration in an Era of Accountability. 
Arts Education Policy Review, 107(4), 3.

Montessori, M. (1975). Dr. Montessori's Own Handbook (14th, 1st Schocken Edition ed.). New York: Schoecken.

National Academy of Engineering [NAE]. (2004). The engineer of 2020: Visions of engineering in the new century. Washington, DC: National Academies Press.

National Academy of Engineering [NAE]. (2005). Educating the engineer of 2020: Adapting engineering education to the new century. Washington, DC: National Academies Press.

National Association for Sport and Physical Education [NASPE]. (2004). Moving into the Future: National Standards for Physical Education (2nd ed.). Reston, VA: Author.

National Council of Teachers of Mathematics [NCTM]. (1995). Assessment standards for school mathematics. Reston, VA: Author.

National Council of Teachers of Mathematics [NCTM]. (2000). Principles and standards for school mathematics. Reston, VA: Author.

National Research Council [NRC]. (1996). National science education standards. Washington, DC: National Academy Press.

National Research Council [NRC]. (2012). A Framework for $K-12$ science education: Practices, crosscutting concepts, and core Ideas. Washington, DC: The National Academy Press.

OECD. (2007). PISA 2006 Science Competencies for tomorrow's world. Volume 1: Analysis. Paris: OECD.

OECD (2010). Education at a glance: OECD indicators. Paris: OECD.

Onishi, N. (April 2, 2006). In a Wired South Korea, Robots Will Feel Right at Home http://www.nytimes.com/2006/04/02/world/asia/ 02robot.html Accessed: April 20, 2011

Paulos, J. A. (1995). A mathematician reads the newspaper. New York: Basic Books Harper Collins.

Petrina, S. (1998). Multidisciplinary technology education. International Journal of Technology and Design Education, 8(2), 36.

Pinch, T., \& Bijker, W. E. (1994). Social
Construction of Facts and Artifacts: Or How the Sociology of Science and the Sociology of Technology Might Benefit Each Other.

Rogers, C. (1969). Freedom to Learn: A View of What Education Might Become (1st ed.). Columbus, OH: Charles Merill.

Ruggiero, V. R. (1988). Teaching thinking across the curriculum. New York: Harper \& Row.

Rutherford, F.J. \& Ahlgren, A. (1989). Science for all Americans. New York: Oxford University Press.

Salinger, G. L. (2005). The engineering of technology education. The Journal of Technology Studies.

Sanders, M. (2006). A rationale for new approaches to STEM education and STEM education graduate programs Paper presented at the 93rd Mississippi Valley Technology Teacher Education Conference. Section IV: Issues in STEM Education.

Sanders, M., Kwon, H., Park, K. \& Lee, H. (2011). Integrative STEM (Science, Technology, Engineering, and Mathematics) education: Contemporary trends and issues. Secondary Education Research, 59(3), 729-762.

Wicklein, R. C. S., John W. . (1995). Case Studies of Multidisciplinary Approaches to Integrating Mathematics, Science and Technology Education. Journal of Technology Education, 6(2).

Wiggins, G. P., \& McTighe, J. (2005). Understanding by design (2nd ed.). Alexandria, VA: Association for Supervision and Curriculum Development.

Yakman, G, (2008). ST $\Sigma @$ M Education: an overview of creating a model of integrative education. Pupils Attitudes Towards Technology 2008 Annual Proceedings. Netherlands.

Zuga, K. (1993). A role for alternative curriculum theories in technology education. Journal of Industrial Teacher Education, 30(4), 19. 